\title{
ANÁLISE COMPARATIVA ENTRE O TRATAMENTO TÉRMICO (TÊMPERA) E O TRATAMENTO TERMOQUÍMICO (CEMENTAÇÃO) REALIZADO EM AÇO 1040
}

\author{
Pedro Alexandre Pinto Celestino \\ Formando em Tecnologia em Materiais pelo CEFET-RN e Estudante de Engenharia \\ Mecânica na UFRN \\ pedroalexandre_rn@hotmail.com
}

Renata Carla Tavares Santos Felipe

Professora do Departamento de Tecnologia Industrial do CEFET-RN

rcfelipe@cefetrn.br

Tércio Graciano Machado

Professor Substituto do Departamento de Tecnologia Industrial do CEFET-RN

gracianomil@hotmail.com

\section{RESUMO}

O objetivo é analisar, do ponto de vista estrutural e das propriedades mecânicas, os resultados obtidos com a realização do tratamento térmico de têmpera e o tratamento termoquímico de cementação realizado em aço 1040. Foram realizados ensaio de dureza Rockwell superficial (30 N) em todas as amostras, além da análise micrográfica, verificando-se a microestrutura obtida pela realização desses tratamentos; comparando-se com um padrão previamente estabelecido. Comprovou-se, através da análise dos dados obtidos, que ocorreu o aumento considerável da dureza nas peças, bem como a visualização da mudança estrutural sofrida com esses tratamentos.

Palavras-chaves: têmpera, cementação, micrográfica, Rockwell superficial.

\section{COMPARATIVE ANALYSIS BETWEEN THE THERMAL TREATMENT (STATE OF HARDENESS) AND TERMOQUIMICO TREATMENT (CEMENTATION), CARRIED THROUGH IN STEEL 1040.}

\begin{abstract}
The objective is to analyze, of the structural point of view and the mechanical properties, the results gotten with the accomplishment of the thermal treatment of state of hardeness and the term chemistry treatment of cementation carried through in steel 1040. They had been carried through superficial rockwell hardness test $(30 \mathrm{~N})$ in all the samples, beyond the micrographical analysis, verifying it microstructure gotten for the accomplishment of these treatments; comparing itself with a standard previously established. One proved, through the analysis of the data gotten, that occurred the considerable increase of the hardness in the parts, as well as the visualization of the suffered structural change with these treatments.
\end{abstract}

Keywords: state of hardeness, cementation, micrographical, superficial Rockwell . 


\section{ANÁLISE COMPARATIVA ENTRE O TRATAMENTO TÉRMICO (TÊMPERA) E O TRATAMENTO TERMOQUÍMICO (CEMENTAÇÃO) REALIZADO EM AÇO 1040}

\section{Introdução}

Os materiais ferrosos encontrados no comércio, na maioria das vezes, antes de sua utilização final, são submetidos a diferentes tratamentos térmicos ou termoquímicos. Estes tratamentos podem ser descritos como, procedimentos utilizados para modificação da estrutura interna ou obtenção de nova formação estrutural do material.

O tratamento térmico de têmpera consiste num resfriamento brusco do material, após ter atingido a temperatura de austenitização. Na têmpera obtém-se a estrutura martensita, com a finalidade de melhorar as propriedades mecânicas dos metais. Assim podemos aumentar a dureza, de maneira prática, de modo que proporcione uma maior resistência ao desgaste, à abrasão e dessa forma aumentando sua durabilidade e confiabilidade na conclusão de projetos.

A cementação é certamente o método mais antigo para endurecimento superficial de aços. Dados históricos revelam que tem sido usado desde a época do Império Romano. Basicamente, o processo consiste em aumentar o teor de carbono em uma fina camada na superfície da peça e posterior tratamento de têmpera e revenido. Assim, se o aço é de baixo carbono, apenas a camada superficial é endurecida e o interior mantém as características de ductilidade e tenacidade. Isso proporciona uma combinação das propriedades desejáveis de resistência ao desgaste e estabilidade estrutural.

Para verificar qual a estrutura obtida após a aplicação dos tratamentos térmicos e termoquímicos foi feito um estudo micrográfico do material, e assim obtendo as fotos da formação interna, podemos fazer uma comparação e qualificarmos que modificação foi observada. De certa forma a micrografia consiste no estudo dos produtos metalúrgicos, com o auxílio do microscópio, permitindo observar a granulação do material, a natureza,forma, quantidade e distribuição dos diversos constituintes ou de certas inclusões, etc. Estas observações são de grande utilidade prática.

E na etapa para classificar o quanto as propriedades mecânicas obtidas significaram em termo de valores os resultados que favoreçam o material, proporcionando melhorias no desempenho estrutural. Foi feito o ensaio de dureza Rockwell Superficial (30N) para verificarmos a eficácia, e qual tipo de tratamento terá uma melhor relação no aumento das propriedades mecânicas.

No ensaio Rockwel , a carga do ensaio é aplicada em etapas, ou seja, primeiro se aplica uma pré-carga, para garantir um contato firme entre o penetrador e o material ensaiado, e depois aplica-se a carga do ensaio propriamente dita. Neste trabalho foi feito ensaios de dureza, Rockwell superficial com pré-carga de 3Kgf e carga de 30Kgf. A leitura do grau de dureza é feita diretamente num mostrador acoplado à máquina de ensaio, de acordo com uma escala predeterminada, adequada à faixa de dureza do material. 
O valor indicado na escala do mostrador é o valor da dureza Rockwell. Este valor corresponde à profundidade alcançada pelo penetrador, subtraída a recuperação elástica do material, após a retirada da carga maior, e a profundidade decorrente da aplicação da précarga.Em outras palavras: a profundidade da impressão produzida pela carga maior é a base de medida do ensaio Rockwell.

\section{Material e métodos}

Inicialmente foi selecionada uma barra de aço com médio teor de carbono - Aço 1040, a qual foi primeiramente cortada transversalmente em partes previamente calculadas (serra mecânica). Na etapa seguinte, estas foram levadas para o torno mecânico com o objetivo de deixá-las faceadas; deixando-as com a mesma espessura. Após isso estas foram limadas nas faces do hexágono para retirar toda a superfície oxidada (ferrugem), seguida de um pré-lixamento a seco para retirada das ranhuras deixadas pelo torno mecânico. Na figura 01 podemos visualizar o desenho do corpo de prova fabricado.
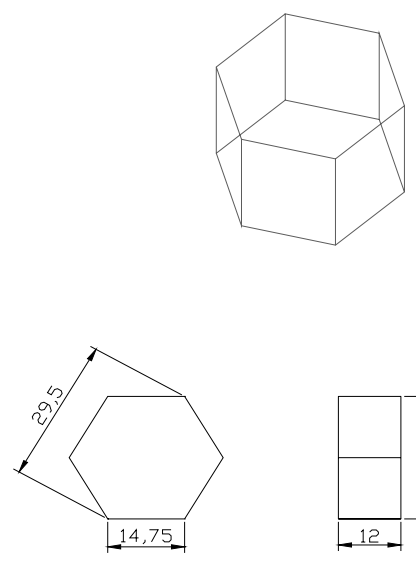

\section{Figura 01 - Visão tridimensional; e medidas do corpo de prova.}

Após essa etapa inicial estas amostras foram acondiconadas em um recipiente de plástico contendo um óleo lubrificante e anti-corrosivo, fabricante Havoline A-50, o qual preservou as peças sem nenhum indício de oxidação, até a sua posterior utilização.

E assim sucessivamente, foram subdivididos em três grupos de estudo, com seis amostras cada. O primeiro grupo é composto de seis amostras, as quais serão consideradas como o padrão do trabalho. No segundo grupo foram feitos os tratamentos de têmpera em óleo. E no terceiro grupo foi feito o tratamento termoquímico de cementação sólida em caixa. Estes tratamentos térmicos foram feitos em forno resistivo com capacidade de atingir temperaturas da ordem de $1250^{\circ} \mathrm{C}$. 
A têmpera foi o primeiro tratamento a ser trabalhado, pois se torna mais simples e necessita de menos recursos do que a cementação. Foram selecionadas seis amostras do material e distribuídas dentro do forno resistivo uniformemente, o qual foi fechado e ligado. As peças foram aquecidas progressivamente de acordo com o aquecimento do próprio forno. E quando se atingiu a temperatura de austenitização para o aço 1040, ou seja, por volta de $830^{\circ} \mathrm{C}$, que começou a marcar o tempo de vinte minutos, para que ocorra uma completa transformação de ferrita para austenita, e assim conseqüentemente uma perfeita homogeneidade da estrutura.

Após os vinte minutos, as peças foram retiradas uma de cada vez e submetidas a um resfriamento brusco em óleo, com finalidade de formar a estrutura martensita.

Depois da têmpera foi feito o revenimento, o qual foi feito numa temperatura de $250^{\circ} \mathrm{C}$ no mesmo forno resistivo, a fim de aliviar as tensões contidas no material devido ao resfriamento brusco.

A cementação foi realizada numa mistura carbonizante formada por carvão vegetal e de um pó para cementação, composto por fundentes e ativadores da reação. A caixa foi fechada o melhor possível, para que haja o mínimo escapamento possível dos gases gerados no interior da caixa. Após atingir a temperatura da $1000^{\circ} \mathrm{C}$, deixou-se por 4 horas de permanência à temperatura constante a fim de formar uma camada com certa profundidade de penetração de carbono e formação de carbonetos de ferro que elevassem a dureza das amostras. E, após esse tempo de permanência, as amostras foram resfriadas dentro do próprio forno para que finalizassem de vez a consolidação de uma camada cementada com profundidade de aproximadamente de dois $\mathrm{mm}$, como pode ser visto na figura 02.

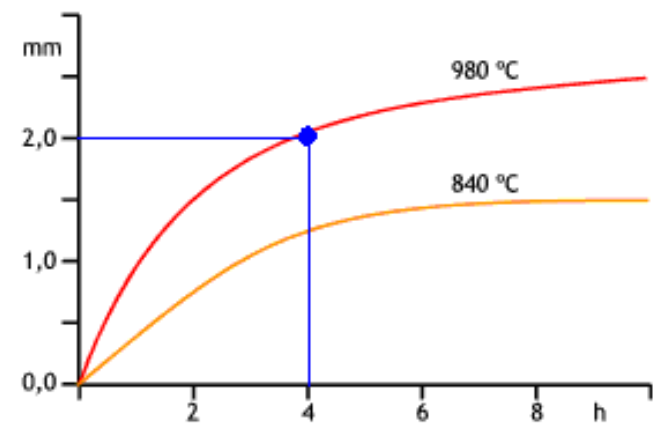

Figura 02- A camada cementada prevista a $1000^{\circ} \mathrm{C} / 4 \mathrm{~h}$.

Foi selecionada uma amostra de cada situação ( $1^{\mathrm{a}}$-Referência, 2 ${ }^{\mathrm{a}}$-Têmpera Óleo, $3^{\mathrm{a}}$ Cementação) para ser analisada metalograficamente. Como as amostras já estavam planas, as mesmas foram colocadas em moldes para receber a resina (termofixa) que, quando misturada com o catalisador, tem um processo de cura rápido; sendo em seguida embutidas. Após um período de 24 horas, realizou-se o lixamento dessas amostras. 
O lixamento foi iniciado com uma lixa de $\mathrm{N}^{\circ} 100$, tomando-se cuidado de sempre antes de passar para a próxima lixa, verificar com uma luneta (aumento de 10 vezes) se todos os riscos estavam no mesmo sentido. Esse procedimento foi realizado em todas as amostras e, na seqüência, foram utilizadas as lixas de número 220, 320, 400, 500 e 600 . Posteriormente foi realizado um pré-polimento para facilitar e diminuir o tempo na politriz. As lixas utilizadas para o pré-polimento foram as de $\mathrm{n}^{\circ} 1000$ e 1200; conferindo um espelhamento com e reduzindo significativamente os riscos na superfície do metal.

Na próxima etapa os corpos de prova foram para a máquina de polimento (politriz), onde foi feito o polimento com o auxílio do um aglomerante de alumina, sendo realizado posteriormente o ataque químico. Esse ataque foi feito com o NITAL 2\% (2\% ácido nítrico e 98\%de álcool etílico), revelando os contornos de grão de ferrita e nas estruturas de martensita com presença de ferrita.

A análise micrográfica foi realizada em microscópio óptico, com aumento de 100, 200 e 400 vezes. Nas figuras 04, 05 e 06, temos a micrografia da estrutura da referência, com aumentos de 100, 200 e 400 vezes, respectivamente.

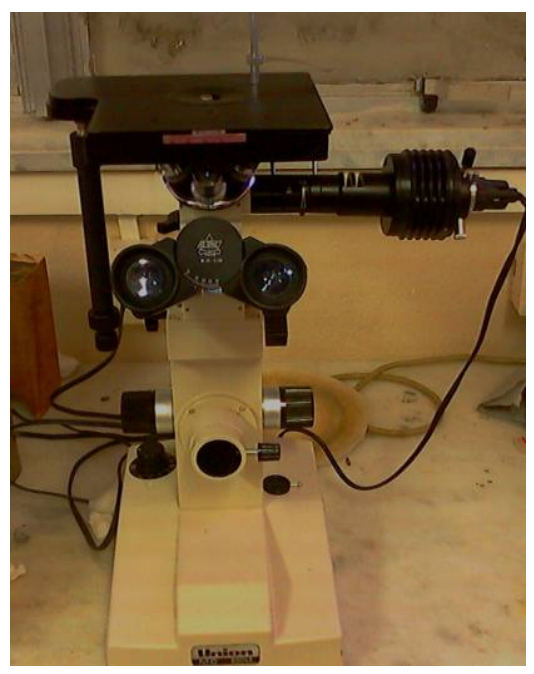

Figura 03- Microscópio Óptico.

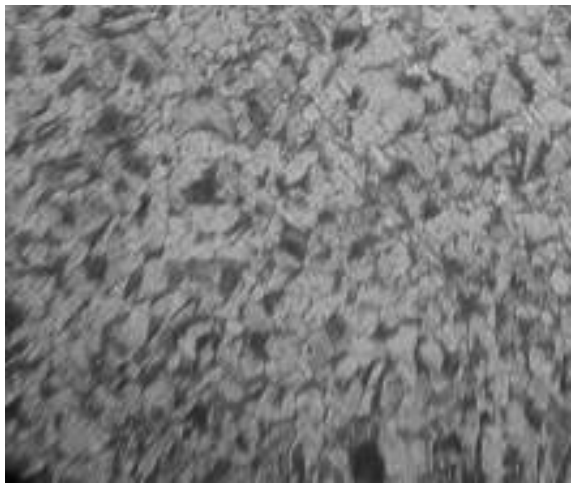


Figura 04 - Aço 1040, aumento de100X, ataque com NITAL 2\%.

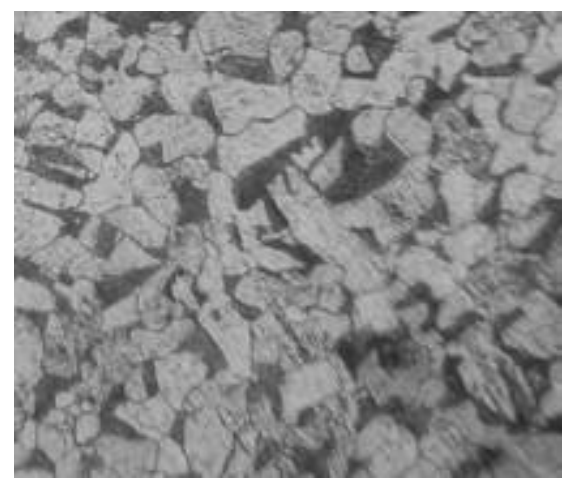

Figura 05 - Aço 1040, aumento de200X, ataque com NITAL $2 \%$.

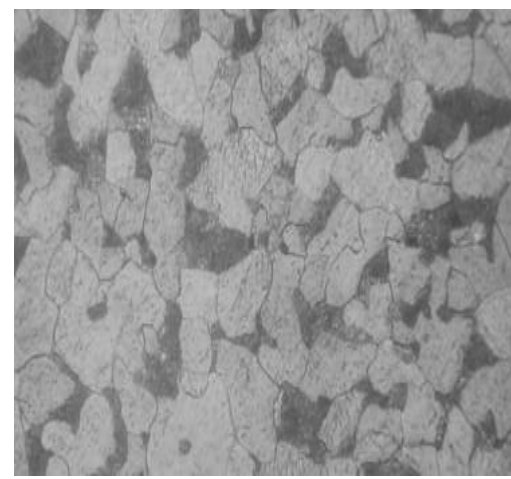

Figura 06 - Aço 1040, aumento de 400X, ataque com NITAL 2\%.

Nas figuras 07, 08 e 09, temos a micrografia da amostra submetida à têmpera em óleo, com aumentos de 100, 200 e 400 vezes, respectivamente.

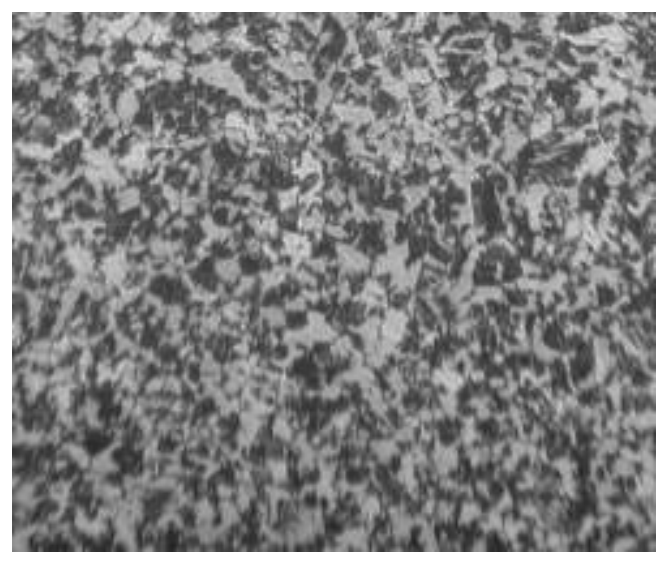


Figura 07 - Aço 1040 temperado em óleo, aumento de 100X, ataque com NITAL 2\%.

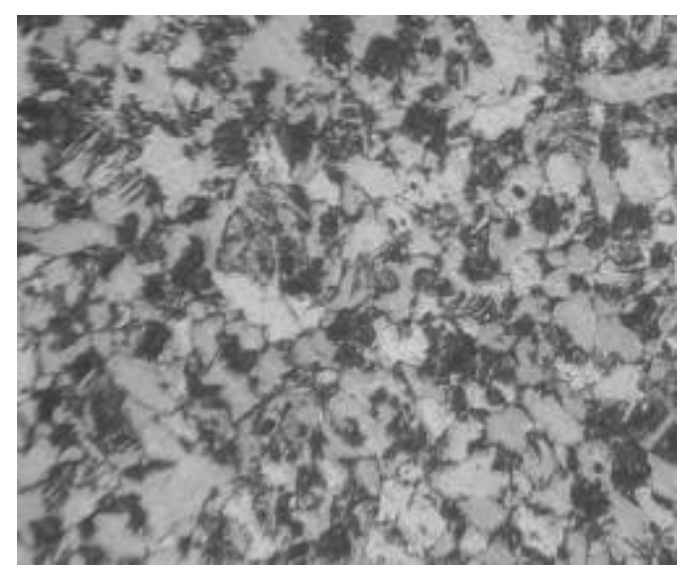

Figura 08 - Aço 1040 temperado em óleo, aumento de 200X, ataque com NITAL 2\%.

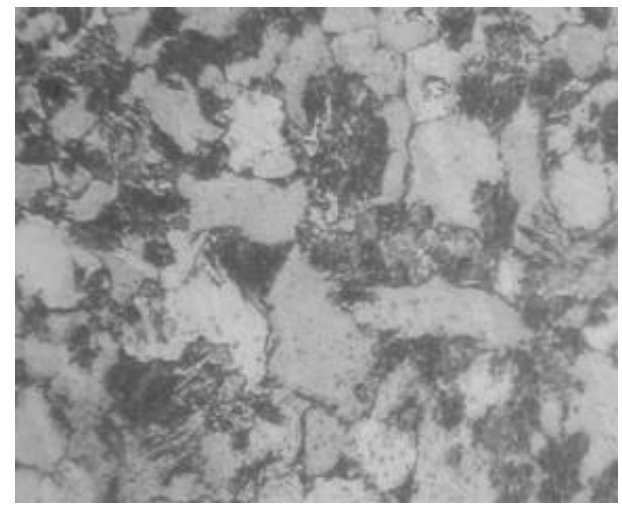

Figura 09 - Aço 1040 temperado em óleo, aumento de 400X, ataque com NITAL 2\%.

Na figura 10, temos a fotografia da amostra submetida à cementação por 4 horas à $1000^{\circ} \mathrm{C}$, com aumento de 100 vezes. 


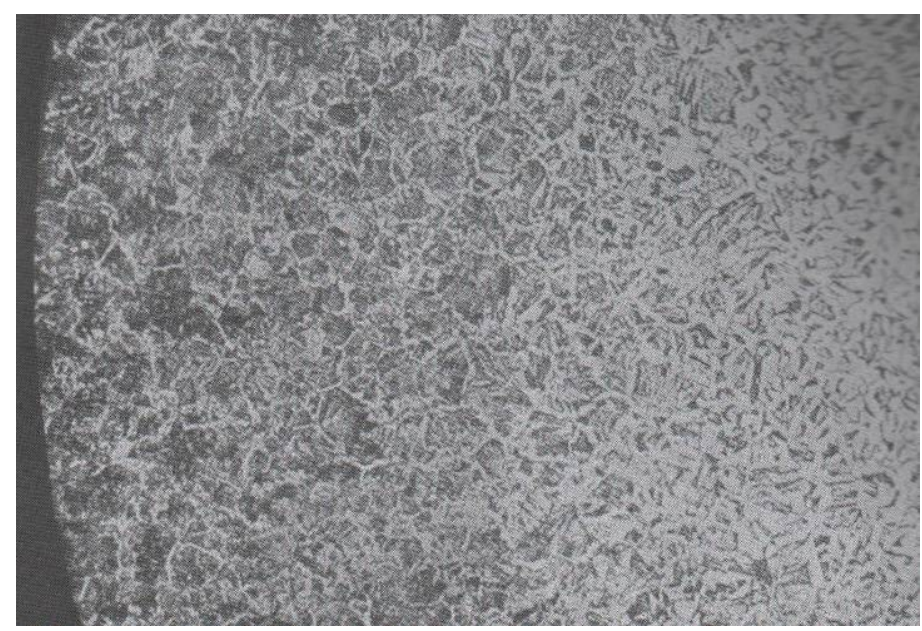

Figura 10 - Aço 1040 cementado por4 horas à $1000^{\circ} \mathrm{C}$, aumento de $100 \mathrm{X}$, ataque com NITAL $2 \%$.

Na verificação da dureza o equipamento utilizado foi o Durômetro Rockwell Durotwin 963 - 102 R (figura 11). Foram tomados dez pontos por corpo de ensaio, com a finalidade de obter-se uma maior confiabilidade na determinação da dureza.

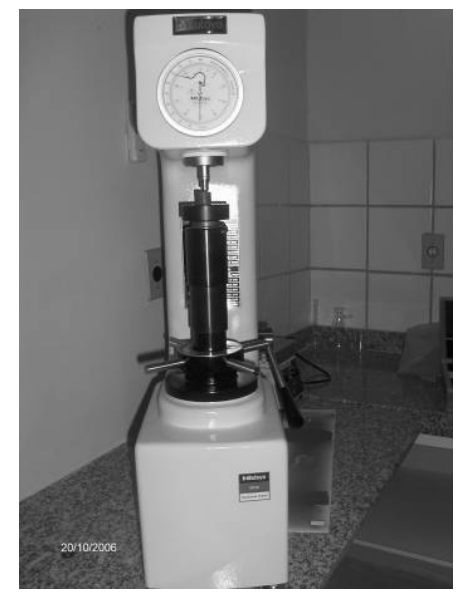

Figura 11 - Durômetro Rockwell Durotwin - 963 - 102 R

\section{Resultados e discussões}

Verificamos, analisando as micrografias, que na têmpera em óleo ocorreu a precipitação da estrutura martensita, estrutura que tem por finalidade aumentar a dureza do aço. Dessa forma, podemos comprovar a temperabilidade do aço 1040.

Nas amostras cementadas, foi possível, além da dureza superficial, também visualizar a camada cementada com profundidade de aproximadamente $2 \mathrm{~mm}$, produzindo uma dureza superficial desejável; permanecendo o núcleo com suas características iniciais preservadas. Como o aço é de médio teor de carbono, a elevação da dureza não foi tão 
acentuada quanto o resultado do tratamento de têmpera. Neste tratamento as amostras apresentaram dureza inferior aos da têmpera em óleo. Como os aços adequados para cementação são aqueles com teor médio de carbono igual ou inferior a 0,25\%, concluímos que os resultados obtidos foram satisfatórios. Contudo, fica evidente que podemos aplicar a cementação sólida em caixa, desde que sejam realizados com atmosfera controlada e com um rigoroso controle da temperatura e tempo de aplicação.

Na tabela 1 podemos visualizar a elevação da dureza.

\section{Tabela 1 - Resultados obtidos em Rockwell Superficial com pré-carga de 3 Kgf e carga de $30 \mathrm{Kgf}$.}

\begin{tabular}{|c|c|c|c|}
\hline \multicolumn{4}{|c|}{$\begin{array}{c}\text { Mitutoyo Durômetro Rockwell 963-102R } \\
\text { Rockwell Superficial ( 30N) }\end{array}$} \\
\hline \multicolumn{4}{|c|}{ Pré-carga de 3 Kgf e carga de 30 Kgf } \\
\hline Ensaios & Referência & Têmpera em Óleo & Cementação \\
\hline $1^{\mathbf{o}}$ & 8 & 31,5 & 15,5 \\
\hline $2^{\mathbf{o}}$ & 14,5 & 31,5 & 22 \\
\hline $3^{\mathbf{o}}$ & 12,5 & 28 & 12 \\
\hline $4^{\mathbf{o}}$ & 13 & 35 & 15 \\
\hline $5^{\mathbf{o}}$ & 15 & 36 & 25 \\
\hline $6^{\mathbf{o}}$ & 8 & 34 & 20,5 \\
\hline $7^{\mathbf{o}}$ & 12 & 32 & 17 \\
\hline $8^{\mathbf{o}}$ & 13 & 38 & 22 \\
\hline $9^{\mathbf{o}}$ & 13 & 38 & 18 \\
\hline $10^{\mathbf{o}}$ & 15 & 33 & 33 \\
\hline Média & $\mathbf{1 2 , 4}$ & $\mathbf{3 3 , 7}$ & $\mathbf{2 0}$ \\
\hline
\end{tabular}

\section{Conclusão}

Concluímos através da análise micrográfica, que ocorreram modificações estruturais nas amostras de aço 1040, sendo que na têmpera a óleo observa-se facilmente a formação da estrutura martensítica e, na cementação, ocorreu a formação de uma camada superficial cementada de carbonetos de ferro com espessura média de $2 \mathrm{~mm}$.

No que se refere à obtenção da dureza, observou-se que se deve ter um controle rígido do tempo de execução do tratamento térmico e termoquímico, pois deve haver a completa homogeneização da estrutura. Contudo, esse tempo não deve ser excessivamente longo para não ocorrer o crescimento de grão. Além disso, é importante que a superfície ensaiada da amostra esteja perfeitamente plana, evitando-se erros na determinação da mesma.

Os resultados e análises foram satisfatórios e, tanto a têmpera a óleo como a cementação, poderão ser indicados para a realização do aumento de dureza em peças que necessitem maior resistência mecânica e ao desgaste. Contudo, para o aço 1040 é aconselhável o tratamento de têmpera em óleo, onde a elevação da dureza foi mais acentuada do que na cementação; além de apresentar o custo menor e ser uma técnica mais comumente utilizada, não necessitando de materiais e técnicas específicas para sua aplicação. 
Foi observado que com a realização deste trabalho a grande importância da utilização destes tratamentos para a metalurgia em geral, visto que correspondem a uma das etapas finais de confecção de ferramentas ou elementos mecânicos, evitando-se sua quebra precoce das mesmas.

\section{Referências Bibliográficas}

[1] CHIAVERINI, V. Tecnologia Mecânica: Estrutura e propriedades das ligas metálicas. Vol. 2, Editora McGraw-Hill, São Paulo, 1986.

[2] CHIAVERINI, V. Tecnologia Mecânica: Materiais de construção mecânica. Vol. 3, Editora Makron Books, São Paulo, 1986.

[3] COLPAERT, H. Metalografia dos Produtos Siderúrgicos Comuns, $3^{a}$ Edição, Edgard Blücher, Editora da Universidade de São Paulo, São Paulo-SP, 1974.

[4] CALLISTER, JR. W.D. Ciência e Engenharia dos Materiais, 5a Edição, LTC Editora, São Paulo-SP. 2002.

[5] MEHI, F. R. Metals Handbook - Atlas of Microestruture of Industrial alloys, Vol. 7, 8th Edition, American Society for Metals, USA, 1973.

[6] GARCIA, A.; SPIM, J.A.; SANTOS, C. A. Ensaios dos Materiais, Editora LTC, Rio de Janeiro, 2000.

[7] ASSOCIAÇÃO BRASILEIRA DE NORMAS TÉCNICAS. NBR NM 14b-1: Materiais metálicos - Determinação da dureza Rockwell. Rio de Janeiro, 1990. 